\title{
Microstructural characterization of the $\gamma$-TiAl alloy samples fabricated by direct laser fabrication rapid prototype technique
}

\author{
D SRIVASTAVA \\ Materials Science Division, Bhabha Atomic Research Centre, Mumbai 400 085, India
}

MS received 2 November 2001; revised 16 October 2002

\begin{abstract}
A direct laser fabrication technique (DLF) has been used to fabricate near net shape samples of a $\gamma$-TiAl alloy using gas atomized $\mathrm{Ti}_{48} \mathrm{A1}_{48} \mathrm{Mn}_{2} \mathrm{Nb}_{2}$ alloy powder as a feed stock material. The microstructures of these $\mathrm{Ti}_{48} \mathrm{Al}_{48} \mathrm{Mn}_{2} \mathrm{Nb}_{2}$ laser treated samples have been characterized using optical, scanning (SEM) and transmission electron microscopy (TEM), both immediately after laser fabrication and after heat treatments. The microstructural studies have shown that the microstructure is heterogeneous in nature and extremely fine in comparison with the conventionally processed material. The process parameters such as laser power and laser scanning speed greatly influence the morphology and the microstructure of the laser treated samples. Heat treatments for a number of process conditions have been carried out to examine the stability of the microstructure which remains stable up to $973 \mathrm{~K}$ and rapid grain coarsening occurs at $1273 \mathrm{~K}$. A fully recrystallized and uniform microstructure is obtained after annealing at $1073 \mathrm{~K}$ for $24 \mathrm{~h}$ and compositional heterogeneity present in the laser-fabricated samples is eliminated. Annealing in the $\alpha$ phase field followed by air cooling and annealing in $\left(\alpha_{2}+\gamma\right)$ phase region gives rise to a homogeneous and uniform microstructure. However, the microstructure is much coarser than the microstructure of the DLF samples.
\end{abstract}

Keywords. Titanium aluminide; microstructure; direct laser fabrication; rapid prototyping.

\section{Introduction}

$\gamma$-Titanium aluminide alloys of near equiatomic composition are important candidate materials for high temperature applications, especially in the aerospace and automotive industries (Kim and Dimiduk 1991; Kim 1994; Liu and Maziasz 1998; Loretto et al 1998). However, these alloys have low ductility and toughness at ambient temperature and are difficult to process by conventional processing routes (Kim and Dimiduk 1991; Kim 1994). The difficulty of processing of these materials is also a major factor in limiting the application of these TiAl-based alloys. Metallurgical efforts such as ternary alloying and thermomechanical treatment have been made to improve the room temperature toughness (Loretto et al 1998). It is possible to improve the ductility and toughness of the TiAl $(\gamma)$ alloys through the modification of microstructure (Hu et al 1998a; Kim 1998).

Near net shape technologies have received great deal of interest as possible fabrication methods especially for such difficult to process materials (Deckard and Beaman 1987; Kruth et al 1997; Steen et al 1997). Several methods of rapid prototyping techniques to directly fabricate fully dense metal objects are currently being developed. Some of these are: laser engineering net shape manufacturing (LENS) (Steen et al 1997), selective laser sintering (SLS) (Deckard and Beaman 1987), shape deposition manufacturing (SDM) (Mertz et al 1994) and direct metal deposi- tion (DMD) (Majumdar et al 1997). In the direct laser fabrication (DLF) process, powder particles are sprayed through a nozzle into the spot of a high power focused laser beam to form a molten pool. The part is then driven by a 3-axis CNC stage to generate a three-dimensional part by layer-wise additive processing. A schematic diagram of the technique is shown in figure 1 . Since this process uses powder as a feedstock, problems of chemical and microstructural inhomogeneities inherent in cast material are greatly reduced.

It is known that the properties of $\gamma$-TiAl-based alloys depend strongly on the microstructure such as lamellar spacing, thickness of $\gamma$ and $\alpha_{2}$ lamellae, volume fraction of the $\alpha_{2}$ phase and grain size etc (Maruyama et al 1997; Morris and Leboeuf 1997; Dimiduk et al 1998; Matsuo 1998). Of the types of microstructures which can be obtained in TiAl alloys the fully lamellar is generally regarded as having the most attractive balance of properties, since it offers controllable strengths, good creep and fatigue resistance, good fracture toughness and reasonable room temperature ductility when grain-refined (Kim and Dimiduk 1991; Kim 1994; Liu and Maziasz 1998; Loretto et al 1998). The fully lamellar microstructure is a product of $\gamma$ phase decomposition via the reaction $\alpha \rightarrow \alpha+\gamma \rightarrow$ $\alpha_{2}+\gamma$. However, during continuous cooling or during repeated heating and melting as in direct laser fabrication it is expected that complex microstructure will form. The process parameters used in the DLF process, such as 
deposition rate, laser power and powder feed rate will determine the rate of heating or cooling of the deposited layers. Thus, it is important to understand the role of process parameters on the microstructure of $\gamma$-TiAl alloys (Srivastava et al 1999, 2000).

Cooling after thermomechanical processing or after subsequent heat treatments leads to very specific microstructures, which are dependent on composition and cooling rate (Ramanujan et al 1996; Hu et al 1998b). The complex microstructure of the direct laser fabricated

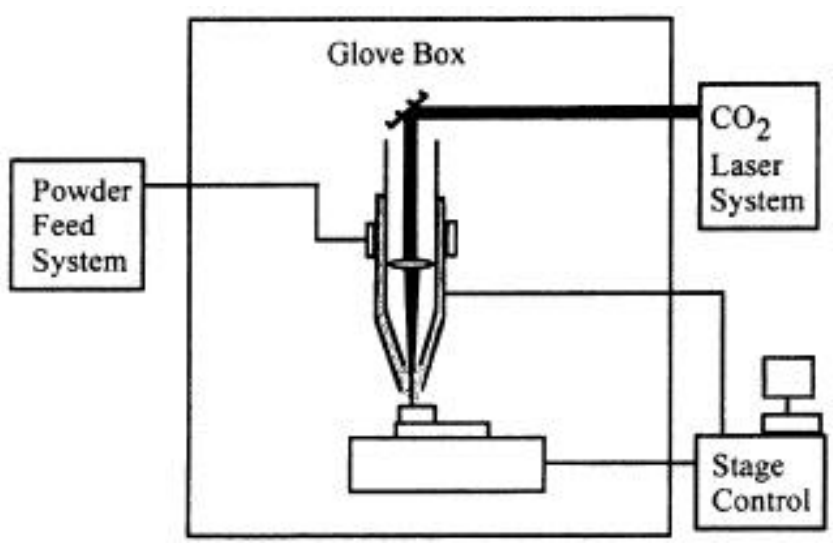

Figure 1. A schematic diagram showing the essential components and basic principle of laser fabrication process. sample can again be changed by subsequent heat treatment and cooling from the heat treatment temperature. A series of heat treatments have been carried out in order to study the stability of microstructure evolved during direct laser fabrication process. Thermal stability of the microstructure of conventionally fabricated material has been studied in detail and reported in the literature (Ramanujan et al 1996; Hu et al 1998b). The aim of this paper is to bring together some experiments, which serve to illustrate the role of heat treatment and process parameters on evolution of microstructure of direct laser fabricated $\mathrm{Ti}_{48} \mathrm{~A}_{48} \mathrm{Mn}_{2} \mathrm{Nb}_{2}$ alloy.

\section{Experimental}

In the present work, a VFA $600 \mathrm{CO}_{2}$ laser unit (power output $0-600 \mathrm{~W}$ ) and a Sulzer Metco type 9MPE closed loop powder feed unit (capacity $1 \mathrm{~g} / \mathrm{min}$ to $100 \mathrm{~g} / \mathrm{min}$ ) were used to melt and deliver the powder material. A NUM $1060 \mathrm{M}$ CNC unit was used to control the workstation and the laser beam movement. The powder is injected directly into the focused laser beam and the laser delivery column and powder nozzle move as an integral unit. An argon gas jet, coaxial with the laser beam axis, was used to shield the melt pool from oxidation. The TiAl base powders were produced in the IRC (Interdisciplinary Research Centre, The University of Birmingham), by gas
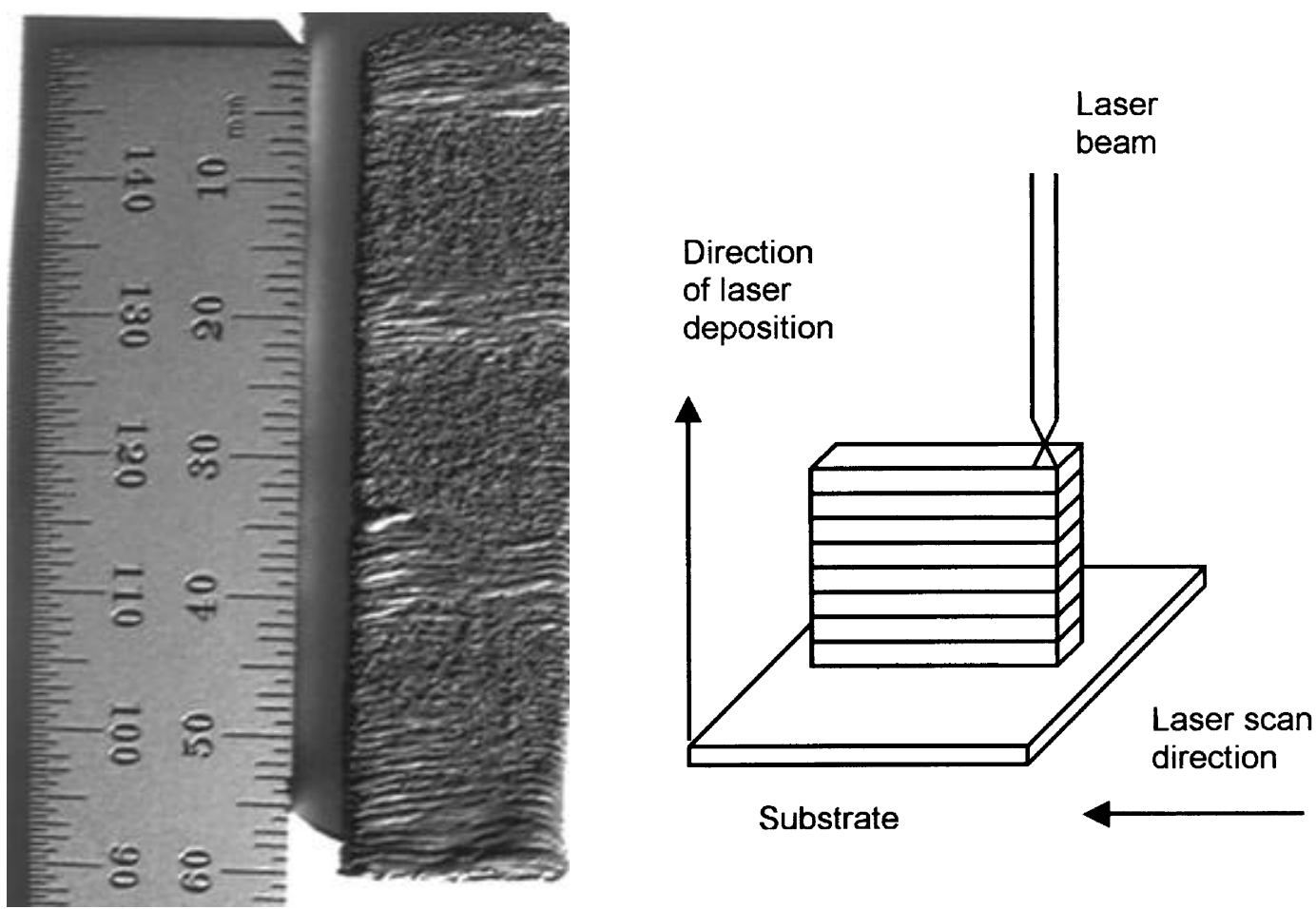

Figure 2. Rectangular strip of TiAl produced by direct laser fabrication process with following processing parameters: laser power, $360 \mathrm{~W}$; laser speed, $8 \mathrm{~mm} / \mathrm{s}$; powder feed rate, $3 \mathrm{~g} / \mathrm{min}$; $z$-increment, $0 \cdot 2 \mathrm{~mm}$; number of layers, 200. 
atomizing re-melted sections of plasma-melted ingots using a bottom-pouring cold wall induction furnace coupled to a gas atomizing facility. The chemical composition (at.\%) of the powder was $\mathrm{Ti}-48 \mathrm{~A} 1-2 \mathrm{Mn}-2 \mathrm{Nb}$ with $600-$ $1000 \mathrm{ppm}$ of oxygen and $0.02-0.03 \mathrm{wt} \% \mathrm{C}$.

Rectangular strips of $\sim 15 \mathrm{~mm}$ width and of varying height were fabricated by depositing successive layers on a substrate of a titanium alloy. Traverses were carried out in alternate directions, and a fixed $z$-increment was used at the end of each traverse. For heat treatment, the laser treated samples were either encapsulated in a quartz tube and heat treated in muffle furnace or heat-treated without encapsulation in a vacuum furnace.

Table 1. The average chemical composition obtained by EPMA of the three different contrast regions shown in figure 3D.

\begin{tabular}{lcccc}
\hline & \multicolumn{4}{c}{ Composition (at.\%) } \\
\cline { 2 - 5 } Regions in DLF samples & $\mathrm{Ti}$ & $\mathrm{Al}$ & $\mathrm{Mn}$ & $\mathrm{Nb}$ \\
\hline Light region (A) & 52.4 & 43.2 & 1.6 & 2.7 \\
Dark region (B) & 46.9 & 49.3 & 1.9 & 1.8 \\
Grey region (C) & 47.7 & 47.9 & 1.9 & 2.5 \\
\hline
\end{tabular}
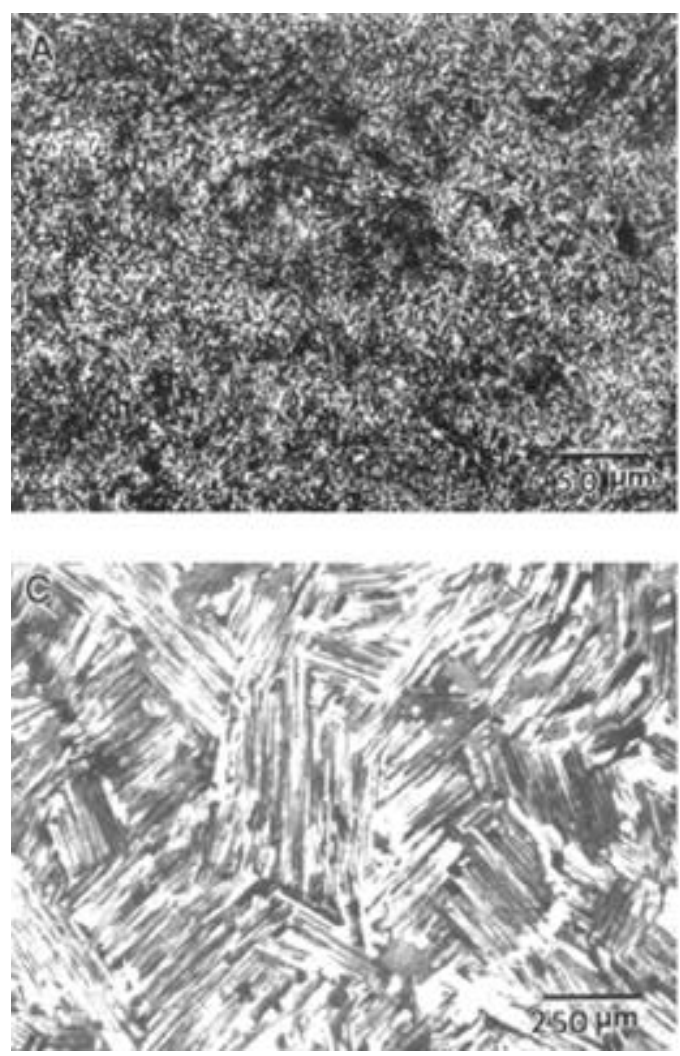

Optical and SEM specimens were prepared by polishing and etching in Kroll's reagent. The TEM specimens were prepared by ion milling in a dual gun Gatan ion mill machine and examined in JEOL 4000FX and Philips CM20 transmission electron microscopes.

\section{Results}

The microstructure of the laser fabricated samples under different experimental conditions have been characterized for those set of samples where complete melting has occurred and fully dense product has been obtained. Simple rectangular plane strip geometry produced by direct laser fabrication process is shown in figure 2 . The strip was fabricated by depositing 200 layers of intermetallic in a single track of $15 \mathrm{~mm}$ length. In the DLF process heat transfer occurs by conduction through the substrate. The rate of heat extraction is expected to decrease with each layer of deposition due to decrease in the temperature gradient between liquid and solid phase. This results in the continuous increase in the melt pool temperature with subsequent layer of deposition (or increase in the strip height). Thus viscosity of the super
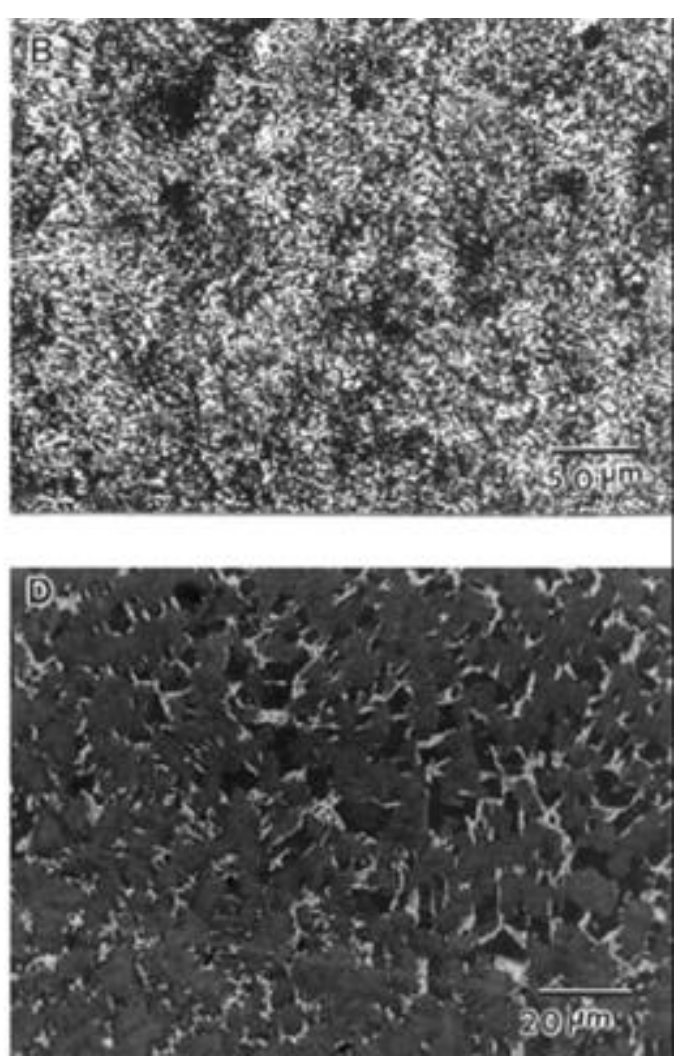

Figure 3. Optical micrograph showing fine microstructure of $\mathrm{Tl}_{48} \mathrm{Al}_{2} \mathrm{Mn}_{2} \mathrm{Nb}$ alloy sample fabricated by DLF process: A. longitudinal section, B. transverse section, C. optical micrograph of a conventionally processed TiAl alloy sample and D. BSE micrograph of TiAl alloy sample fabricated by DLF process (processing parameters for DLF process: laser power, $360 \mathrm{~W}$; laser speed, $8 \mathrm{~mm} / \mathrm{s}$; powder feed rate, $3 \mathrm{~g} / \mathrm{min}$; $z$-increment, $0 \cdot 2 \mathrm{~mm}$; number of layers, 20). 

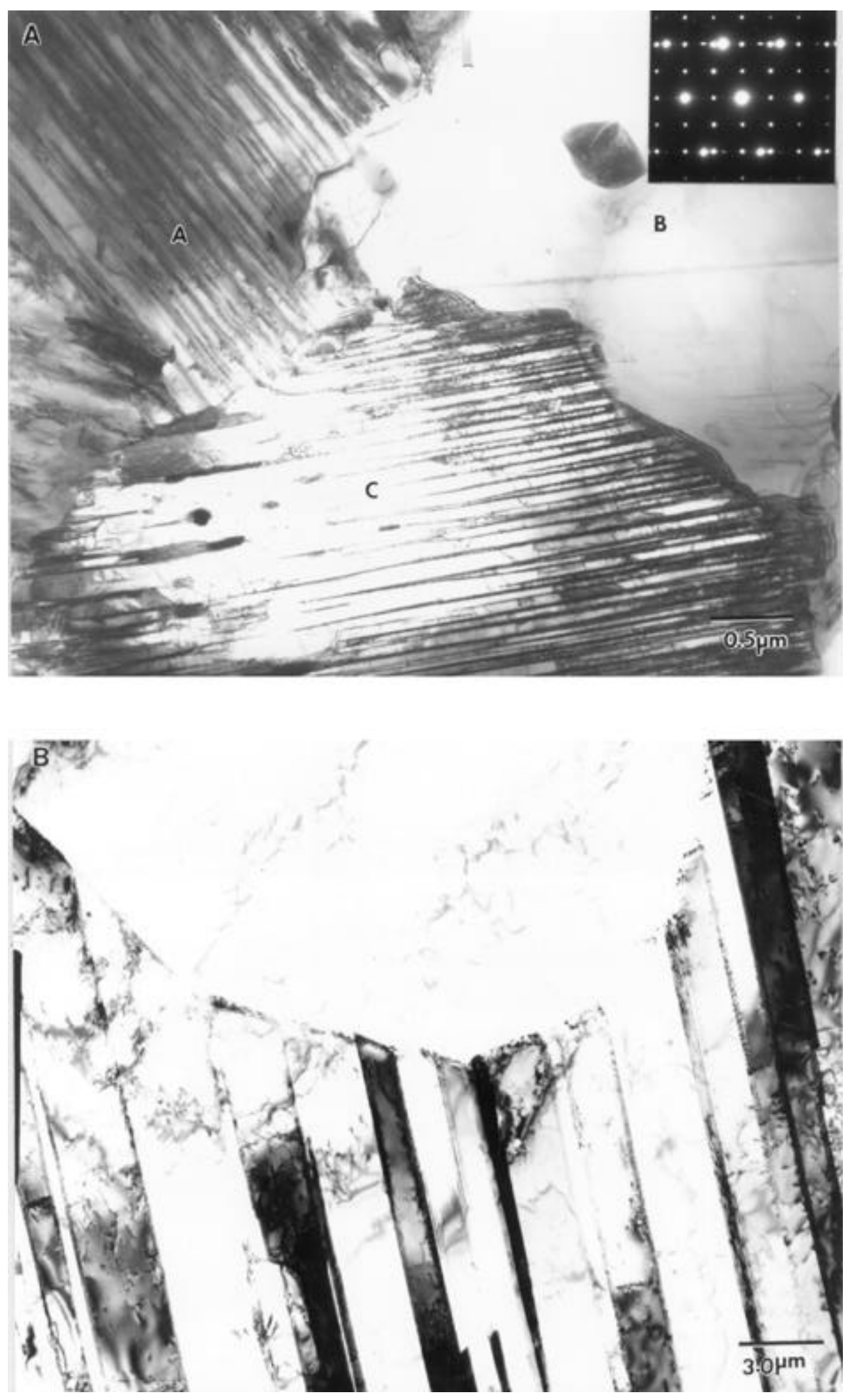

Figure 4. A. Many beam TEM micrograph showing nonuniform microstructure in laser fabricated TiAl material: laser power, $360 \mathrm{~W}$; powder feed rate, $3 \mathrm{~g} / \mathrm{min}$; scanning speed, $480 \mathrm{~mm} / \mathrm{min}$; $z$-increment, $0.2 \mathrm{~mm}$; number of layers, 20 and B. many beam TEM micrograph of a conventionally cast TiAl alloy sample. 
heated melt decreases and melt pool becomes unstable after a certain layers of deposition, which is seen as banded region. Such instability is overcome by reducing the heat input per unit time in the bath by slightly decreasing the laser power or increasing the laser beam scan rate. Strip shown in figure 2, has been built up with 200 layers deposition and such kind of instability was observed after $\sim 50$ layers. Because of this reason only 30 layers were deposited in the microstructural study of TiAl alloy keeping all process parameters constant.

The oxygen content of these laser-fabricated samples was found to be in the range 1500-1800 ppm.

\subsection{Microstructure of direct laser fabricated Ti-Al}

Typical optical micrographs of a direct laser fabricated (DLF) sample in the longitudinal and transverse sections
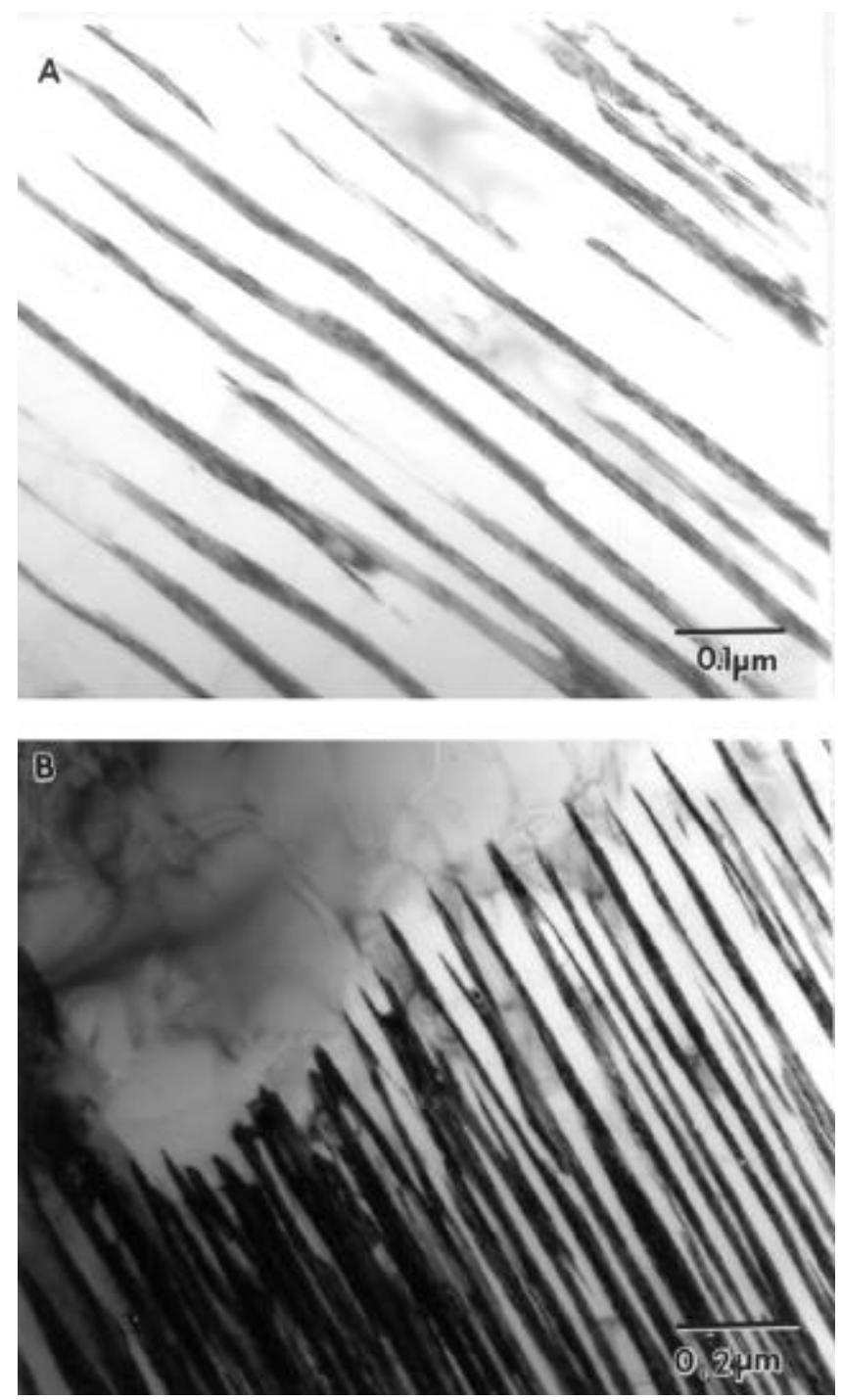

Figure 5. Many beam TEM micrographs showing A. the examples of imperfect lamellae formation and $\mathbf{B}$. growth of $\alpha_{2}$ phase in the $\gamma$ matrix. Power, $360 \mathrm{~W}$; scan rate, $20 \mathrm{~m} / \mathrm{min}$; powder feed rate, $3 \mathrm{~g} / \mathrm{min}$; $z$-increment, $0.3 \mathrm{~mm}$; number of layers, 20 . are shown in figures $3 \mathrm{~A}$ and $\mathrm{B}$, respectively. Figure $3 \mathrm{C}$ shows a typical optical micrograph of conventionally processed (plasma arc melted and forged) sample. From these micrographs it is clear that the microstructure of the laser-fabricated sample consisted of extremely fine
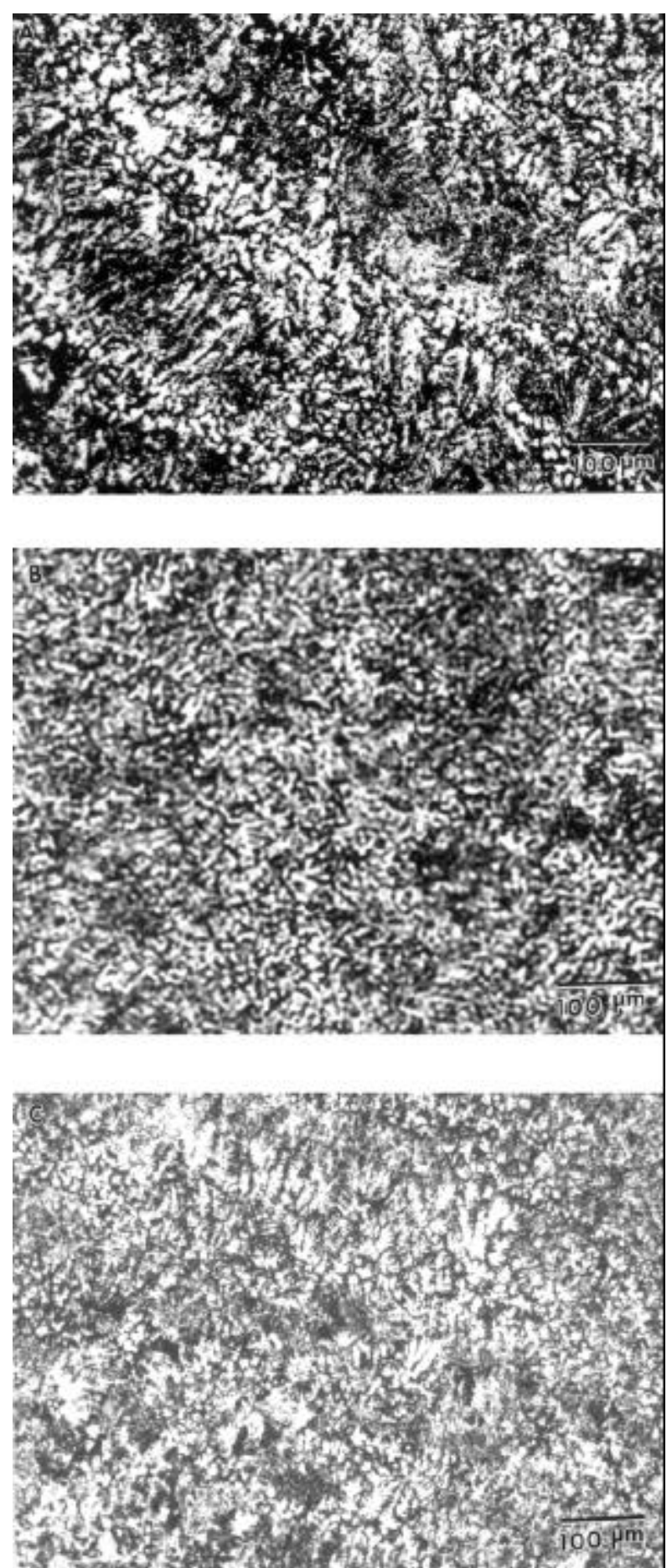

Figure 6. Optical micrograph of DLF samples of $\mathrm{Tl}_{48} \mathrm{Al}_{2}$ $\mathrm{Mn}_{2} \mathrm{Nb}$ alloy fabricated with different laser powers: A. $300 \mathrm{~W}$, B. $360 \mathrm{~W}$ and C. $400 \mathrm{~W}$ (laser speed, $8 \mathrm{~mm} / \mathrm{s}$; powder feed rate, $3 \mathrm{~g} / \mathrm{min}$; $z$-increment, $0.2 \mathrm{~mm}$; number of layers, 20). 
grains. The microstructure appeared to be homogeneous and uniform in both longitudinal as well as in transverse sections of the laser fabricated samples. Because of the very fine microstructure, no further information could be derived from optical micrographs. It did not reveal the presence of the normal two-phase $\left(\alpha_{2}+\gamma\right)$ lamellar structure typical of $\gamma$-TiAl alloys.

Further analysis of the morphologies at higher magnification in back scattered (BSE) micrograph of SEM (figure 3D) of the longitudinal section of the sample showed three distinct contrasts light, dark and grey. The light contrast phase was distributed as thin stringers along the grain boundaries of the grey and dark phases. The grey and dark phases appeared to be equiaxed and uniformly distributed. These equiaxed structures exhibited grain size variation of 2 to $5 \mu \mathrm{m}$ compared with 20 to $100 \mu \mathrm{m}$ in conventionally processed material. The composition of these regions, as determined by electron microprobe analysis (EPMA) in the SEM is given in table 1. From this analysis, it could be seen that the light region was rich in titanium, the dark region had equal concentration of titanium and aluminium and the grey region had a composition between those of dark and bright regions. This analysis suggested that bright region corresponds to $\alpha_{2}$ phase, dark region to $\gamma$ phase and grey region to the mixture of these two phases. BSE images of SEM exhibited the presence of a two-phase microstructure but could not confirm the presence of the typical lamellar microstructure observed in the $\gamma$-TiAl alloys.

Figure 4A shows a typical low magnification TEM micrograph of a DLF sample, which clearly revealed the presence of lamellar morphology of two phases. The microstructure appeared to consist of three distinct types of grains which are fully lamellar, featureless and partially lamellar marked as A, B and C, respectively in the micrograph. Selected area diffraction (SAD) obtained from these regions provides evidence that the featureless regions of the grains marked as $\mathrm{B}$ and $\mathrm{C}$ correspond to $\gamma$ phase and the lamellar region correspond to $\gamma$ and $\alpha_{2}$ phases. The SAD patterns obtained from these regions suggested that the orientation relationship between these two phases is that reported for conventionally produced material (figure 4A). A bright field micrograph of the conventionally processed material obtained under many beam conditions is shown in figure 4B. Comparing the TEM micrograph of conventionally processed and laser fabricated sample, it could be seen that lamellae width and interlamellar spacing of two phases are much smaller in the laser-fabricated sample. The average interlamellar spacing was $30-100 \mathrm{~nm}$ compared with 1 to $2 \mu \mathrm{m}$ in the case of the conventionally processed material. In addition, it was observed that the ratio of the lamellae width of the $\alpha_{2}$ and $\gamma$ phases is much higher in the case of laser fabricated samples (figure 4). In general, the lamellae of $\gamma$ and $\alpha_{2}$ phases were found to be imperfect in DLF samples. It was noticed that the interlamellar spacing varied consi- derably within a given grain in the DLF sample. Some of the $\alpha_{2}$ lamellae were found to terminate at or within $\gamma$ phase. Figure 5A shows examples of formation of imperfect lamellae. The lamellae were found to be of uneven thickness and many of them were found fragmented. Figure 5B shows a partially lamellar grain in which it appears that $\alpha_{2}$ lamellae are growing within the $\gamma$ phase and tapering off before reaching the end of the grain. EDS analysis
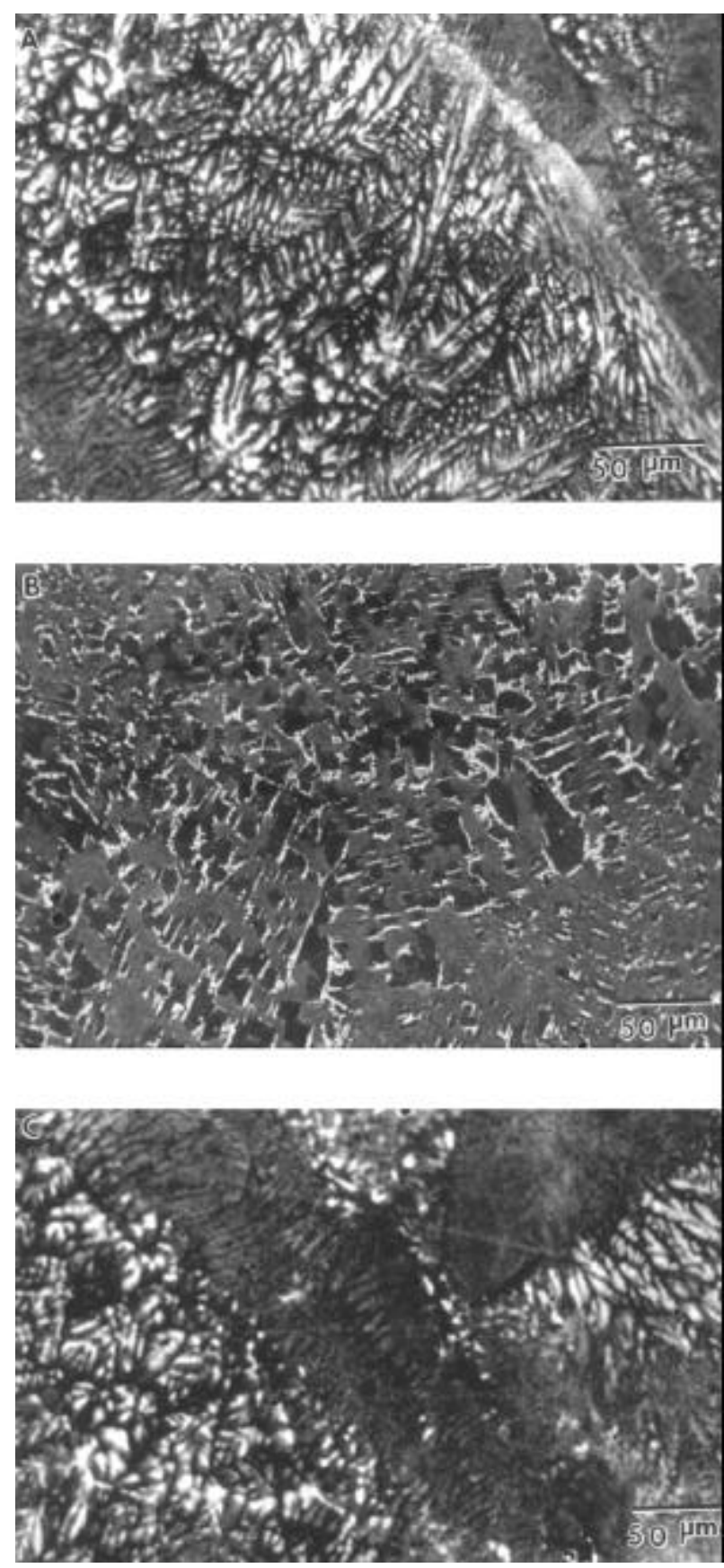

Figure 7. BSE image of DLF samples of $\mathrm{Tl}_{48} \mathrm{Al}_{2} \mathrm{Mn}_{2} \mathrm{Nb}$ alloy fabricated with different laser powers A. $300 \mathrm{~W}$, B. $360 \mathrm{~W}$ and C. $400 \mathrm{~W}$ (laser speed, $8 \mathrm{~mm} / \mathrm{s}$; powder feed rate, $3 \mathrm{~g} / \mathrm{min}$; $z$-increment, $0 \cdot 2 \mathrm{~mm}$; number of layers, 20 ). 
was carried out in TEM to determine the composition of the two phases in different regions. It was observed that composition of the $\gamma$ phase was equiatomic $(\sim 48$ at. $\% \mathrm{Ti}$ and 48 at.\% $\mathrm{Al})$ within the lamellar region and richer in aluminum ( 46 at. $\% \mathrm{Ti}$ and 50 at.\% $\mathrm{Al})$ in the featureless region (figure $4 \mathrm{~A}$ ) in a partially lamellar grain.

\subsection{Effect of processing parameters on microstructure of DLF samples}

It was observed that the important features of this process-uniformity of the build height and width, build modulation and wall edge finish, shrinkage, residual stress, dimensional accuracy and the microstructure-are strongly dependent on the processing parameters such as laser power, laser scanning velocity, $Z$-axis increment and the powder feed rate. In order to study the effect of these processing parameters on the microstructure, DLF samples have been fabricated using the following processing parameters: laser power, 300 to $450 \mathrm{~W}$; scanning speed, 4-12 $\mathrm{mm} / \mathrm{s}$; powder feed rate, $3 \mathrm{~g} / \mathrm{min}$; $z$-increment, $0 \cdot 1-$ $0.2 \mathrm{~mm}$; number of deposited layers, 10-30.
Optical micrographs of the traverse section of the DLF samples of TiAl material fabricated with varying laser power are shown in figure 6. Samples made with low laser power, $300 \mathrm{~W}$ (figure 6A) and high laser power, $400 \mathrm{~W}$ (figure 6C) show dendritic, non-uniform and coarse microstructures. In these samples, in general, the morphology varied from cellular to columnar to dendritic. Samples made with intermediate laser power, $360 \mathrm{~W}$ (figure 6B) consist of very fine, uniform equiaxed microstructure. The microstructure is more clearly seen in higher magnification BSE micrographs in figures 7A-C, respectively. Sample made with low power, $300 \mathrm{~W}$, was showing nearly fully dendritic microstructure (figure 7A). Whereas, sample made with high laser power, $400 \mathrm{~W}$, was exhibiting mixture of dendritic and cellular-dendritic structure. These microstructures did not reveal the presence of two-phase lamellar microstructure. During the chemical analysis of these samples in the SEM, it was observed that dendritic region was rich in titanium and inter-dendritic region was rich in aluminum. This observation indicated that the former region contains higher fraction of the $\alpha_{2}$ phase.
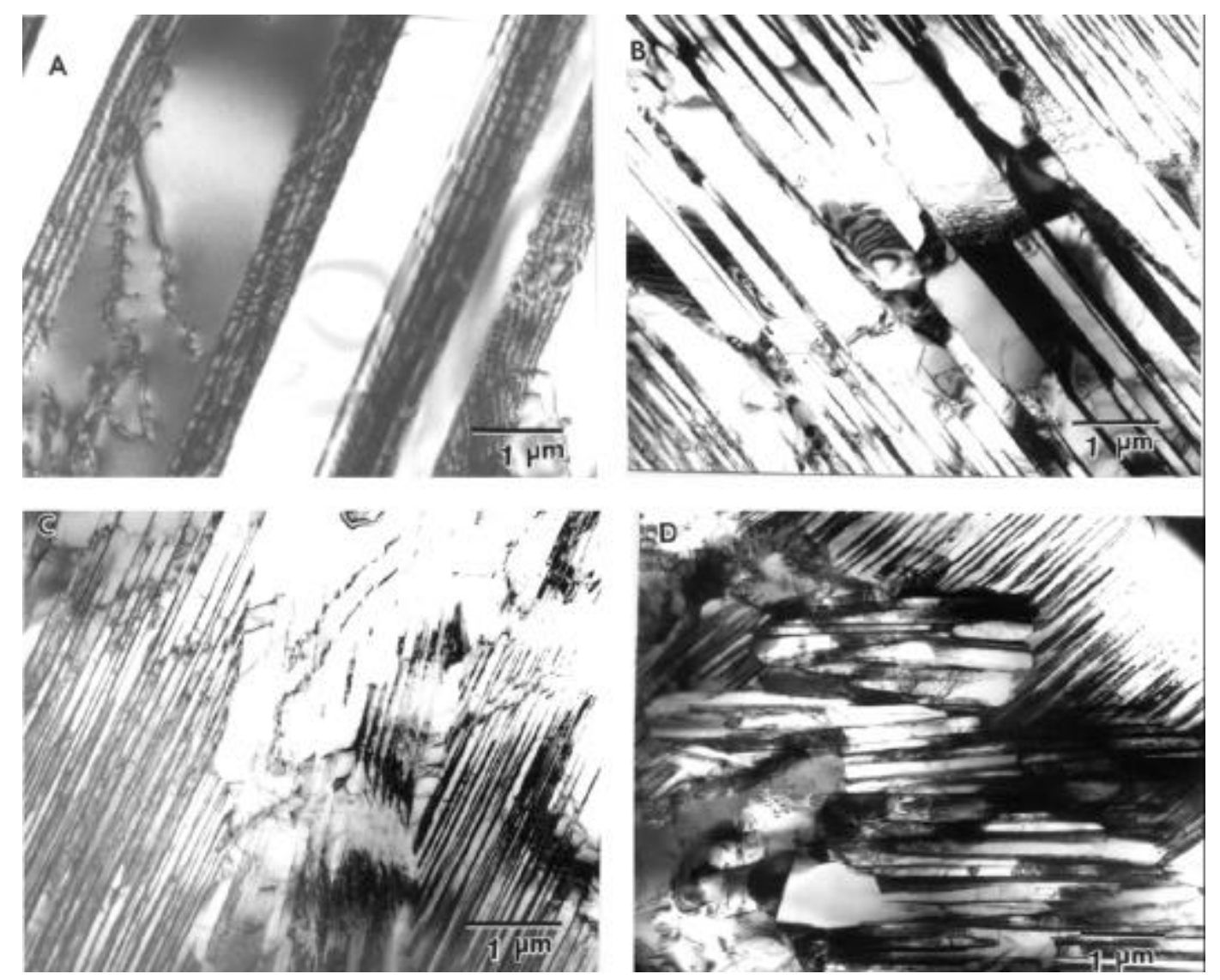

Figure 8. Many beam TEM micrographs showing variation in microstructure of $\mathrm{T1}_{48} \mathrm{Al}_{2} \mathrm{Mn}_{2} \mathrm{Nb}$ alloy as a function of laser power: A. conventionally cast; B-D. DLF samples fabricated with laser power $300 \mathrm{~W}, 360 \mathrm{~W}$ and $400 \mathrm{~W}$, respectively (laser speed, $8 \mathrm{~mm} / \mathrm{s}$; powder feed rate, $3 \mathrm{~g} / \mathrm{min}$; $z$-increment, $0 \cdot 2 \mathrm{~mm}$; number of layers, 20$)$. 

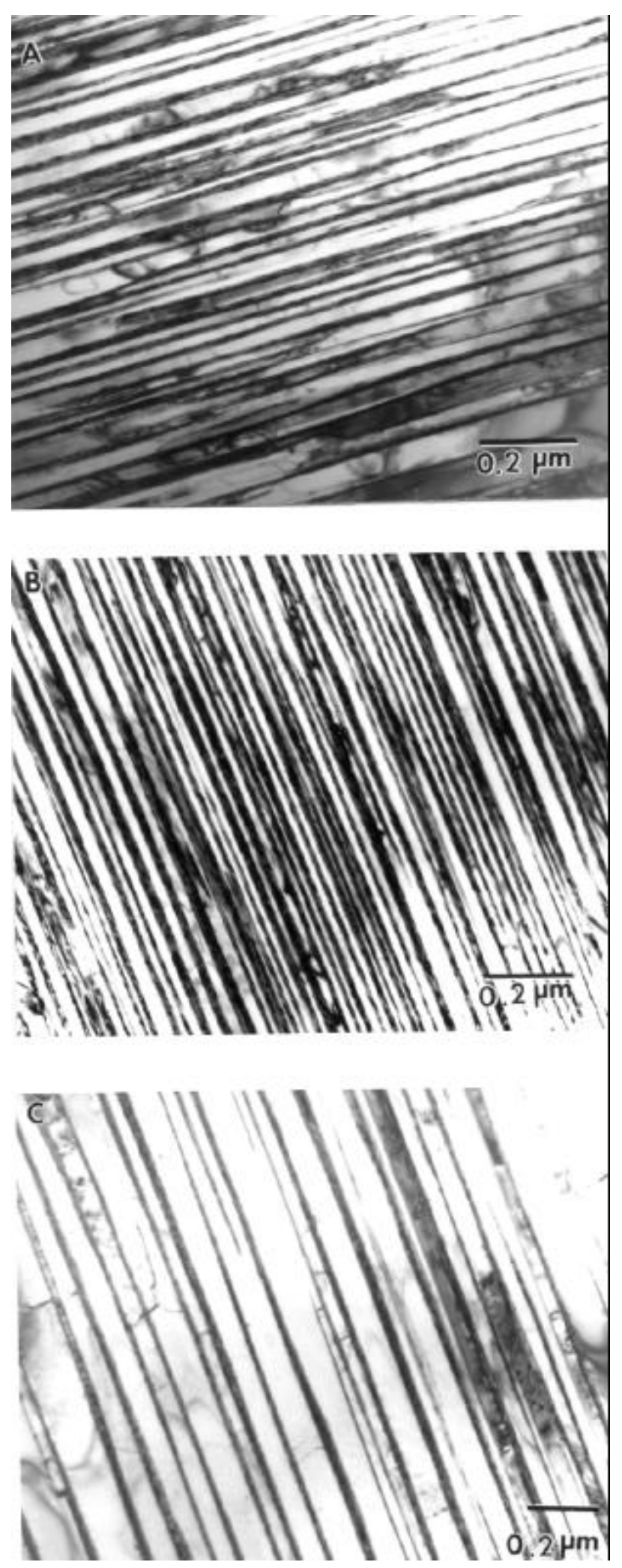

Figure 9. Many beam TEM micrographs of DLF samples of $\mathrm{Tl}_{48} \mathrm{Al}_{2} \mathrm{Mn}_{2} \mathrm{Nb}$ alloy showing variation in the interlamellar spacing and lamellar width processed with laser power: A. $300 \mathrm{~W}$; B. $360 \mathrm{~W}$ and C. $400 \mathrm{~W}$ (laser scanning speed, $8 \mathrm{~mm} / \mathrm{s}$, powder feed rate, $3 \mathrm{~g} / \mathrm{min}$; $z$-increment, $0.2 \mathrm{~mm}$; number of layers, 20).
A typical many-beam TEM micrograph of the conventionally cast $\gamma$-TiAl alloy is shown in figure 8A. TEM micrographs obtained from DLF TiAl samples fabricated with varying laser powers are shown in figures $8 \mathrm{~B}-\mathrm{D}$. Since the dendritic structures were very coarse they could not be observed in TEM study. The general microstructure appeared to be similar in the different regions of the sample. Therefore, it was not possible to correlate the low magnification optical/SEM micrograph to TEM micrograph.

All DLF samples fabricated with different laser powers showed heterogeneous microstructure consisting of lamellar $\left(\alpha_{2}+\gamma\right)$, featureless $(\gamma)$ and partially lamellar $\left(\gamma+\left(\alpha_{2}+\gamma\right)\right)$ phase regions. From figure 8 it could be clearly seen that the microstructure of the DLF sample is greatly influenced by the laser power used to fabricate DLF samples. The morphology of the individual phases and their volume fraction depended on the laser power and the scan speed. The average interlamellar spacing in the DLF samples fabricated using laser powers $300 \mathrm{~W}$, $360 \mathrm{~W}$ and $400 \mathrm{~W}$ was found to be $60-100 \mathrm{~nm}, 30-100 \mathrm{~nm}$ and 100-250 nm, respectively (figure 9).

Figure 10 shows X-ray diffractogram (XRD) of conventionally cast material and DLF sample fabricated using two different laser powers. XRD of conventionally cast material (figure 10A) did not show presence of any prominent peaks of $\alpha_{2}$ phase. Whereas, in the case of DLF samples, (201) $\alpha_{2}$ and (200) $\alpha_{2}$ peaks of the $\alpha_{2}$ phase could be clearly seen (figures 10B-C). The peaks were more prominent in the case of samples fabricated with $360 \mathrm{~W}$ laser power (figure 10C) than those made with $300 \mathrm{~W}$ laser power (figure 10B). Additionally, it could be seen that $(002)_{\gamma}$ and $(200)_{\gamma}$ peaks and $(202)_{\gamma}$ and $(220)_{\gamma}$ peaks in the conventionally cast material were well separated. Whereas, in the case of the laser fabricated samples made with $400 \mathrm{~W}$ these peaks were seen as one peak.

The effect of laser scanning speed on the microstructure of the laser-fabricated sample is shown in figure 11. The variation in the morphology and microstructure between two successively deposited layers in laser fabricated samples were much more predominant, when the laser scan speed was slower (figure 11A). Since the scale of difference in the microstructure was large this aspect was demonstrated by showing low magnification, optical (11A) and high magnification, BSE (11B) micrographs for samples made with low and high traverse speeds, respectively.

\subsection{Microstructure of DLF samples after heat treatment}

The optical micrographs of the DLF samples heat-treated at different temperatures for different duration are shown in figure 12. These DLF samples were fabricated with processing parameters: laser power, $400 \mathrm{~W}$; laser scanning speed, $8 \mathrm{~mm} / \mathrm{s}$; powder feed rate, $3 \mathrm{~g} / \mathrm{s}$; $z$-increment, 
$0.2 \mathrm{~mm}$; and number of layers deposited, 20. The microstructure of the DLF sample heat treated at $973 \mathrm{~K}$ did not change appreciably even after annealing up to $300 \mathrm{~h}$ (figure 12B). Annealing at $1073 \mathrm{~K}$ up to $24 \mathrm{~h}$ also did not show any major change in the microstructure, except slight coarsening of microstructure (figure 12C). When DLF samples were annealed at $1073 \mathrm{~K}$ for longer duration $(100 \mathrm{~h})$, the microstructure appeared to be fully recrystallized and homogeneous (figure 12D). In this sample the dendritic microstructure of the DLF sample was completely eliminated. Annealing at $1273 \mathrm{~K}$ even for $1 \mathrm{~h}$ resulted in the rapid coarsening of the microstructure (figure 12E) and the annealing at this temperature for longer time resulted in the further coarsening of the larger grains at the expense of the smaller grains (figure 12F). A uniform and homogeneous microstructure could not be obtained even after heat treating at $1273 \mathrm{~K}$ for $100 \mathrm{~h}$ (figure $12 \mathrm{~F}$ ).

Higher magnification TEM micrographs of the heattreated DLF samples are shown in figures 13 and 14. The fine lamellar structure typical of a DLF sample is retained in the case of DLF sample heat-treated at $973 \mathrm{~K}$ for $100 \mathrm{~h}$ (figure $13 \mathrm{~A}$ ). In the case of DLF sample, annealed at $1073 \mathrm{~K}$ for $24 \mathrm{~h}$, the microstructure did not change appreciably except slight coarsening of lamellar

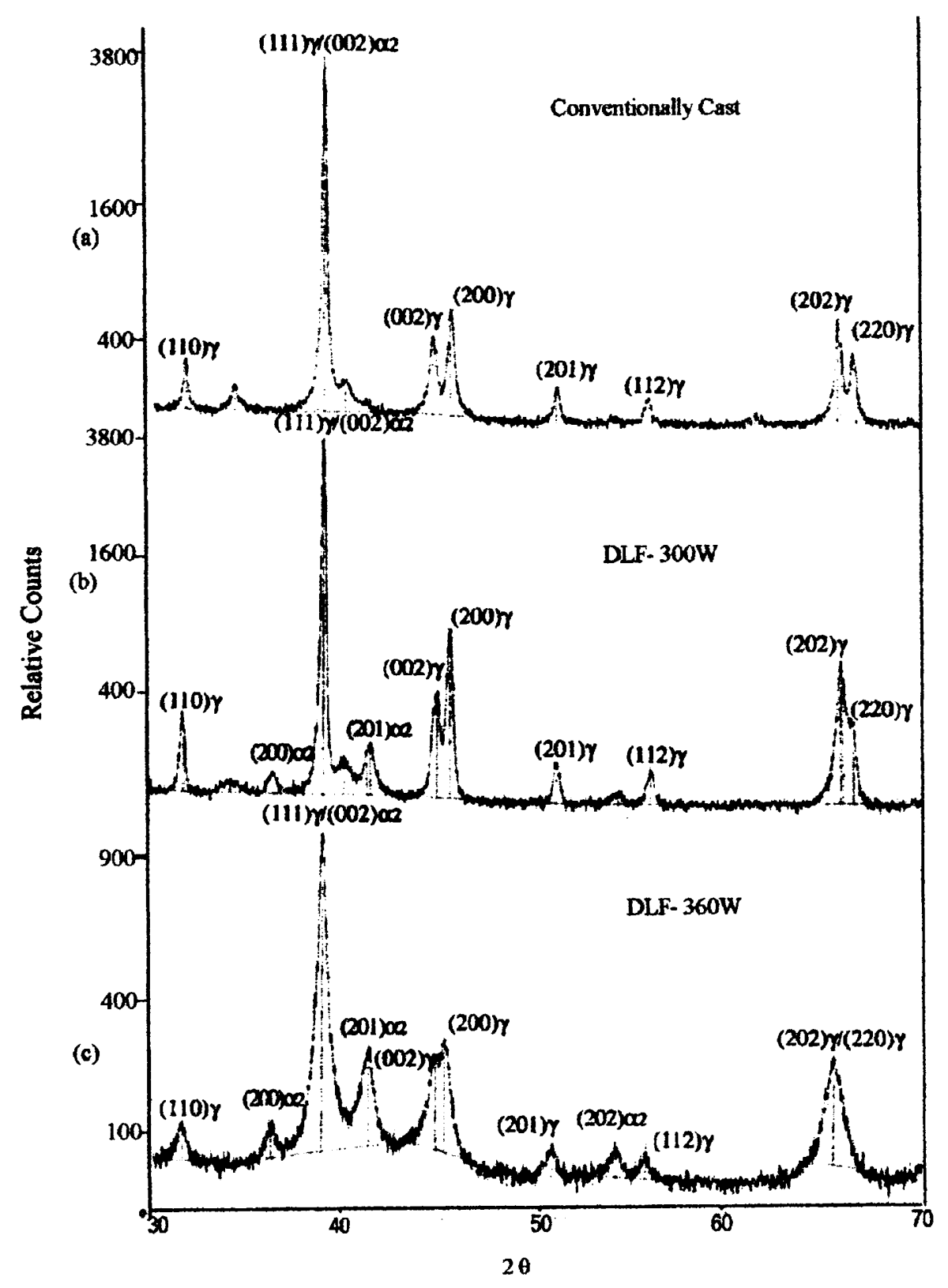

Figure 10. $\mathrm{XRD}$ of $\mathrm{Tl}_{48} \mathrm{Al}_{2} \mathrm{Mn}_{2} \mathrm{Nb}$ alloy samples: A. conventionally cast; $\mathbf{B}$ and $\mathbf{C}$. DLF samples fabricated with laser powers $300 \mathrm{~W}$ and $360 \mathrm{~W}$ (laser speed, $8 \mathrm{~mm} / \mathrm{s}$; powder feed rate, $3 \mathrm{~g} / \mathrm{min}$; $z$-increment, $0.2 \mathrm{~mm}$; number of layers, 20). 
structure (figure 13B). However, DLF samples annealed at $1073 \mathrm{~K}$ for longer, $200 \mathrm{~h}$, duration, showed fully recrystallized microstructure with much coarser lamellar structure (figure 13C). The EDS analysis of these samples in TEM showed that the chemical composition of the $\gamma$ phase was the same in the single phase region and in the two-phase lamellar region. Thus, heat treating at $1073 \mathrm{~K}$ for more than $24 \mathrm{~h}$ resulted in complete elimination of the chemical heterogeneity observed in the DLF microstructure. TEM micrograph of the DLF samples annealed at $1273 \mathrm{~K}$, revealed that the lamellar microstructure of this alloy was virtually completely destroyed (figure 14). A very small number of coarse lamellar $\alpha_{2}$ phases were observed in the matrix of the $\gamma$ phase in the samples annealed for $3 \mathrm{~h}$ (figure 14A). These numbers further decreased when samples were annealed for $24 \mathrm{~h}$ (figure 14B) and $100 \mathrm{~h}$ (figure 14C), respectively. No lamellar $\gamma$ phase was observed in these samples annealed at $1273 \mathrm{~K}$. Figure 15 shows the XRD of the samples annealed at
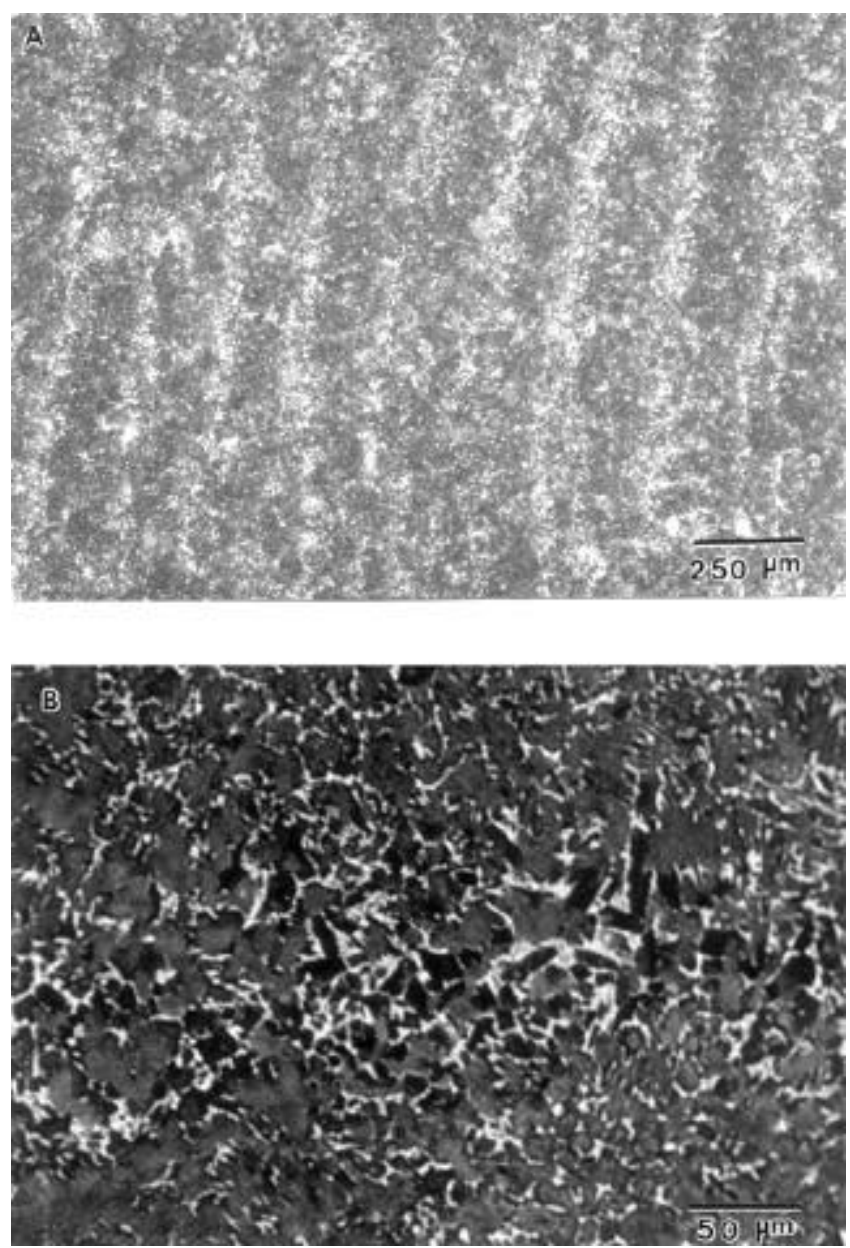

Figure 11. Micrograph of DLF samples of $\mathrm{Tl}_{48} \mathrm{Al}_{2} \mathrm{Mn}_{2} \mathrm{Nb}$ alloy showing variation in the morphology and microstructure processed with laser scanning speed: A. $4 \mathrm{~mm} / \mathrm{s}$ (optical micrograph) and B. $8 \mathrm{~mm} / \mathrm{s}$ (BSE micrograph) (laser power, $360 \mathrm{~W}$; powder feed rate, $3 \mathrm{~g} / \mathrm{min}$; $z$-increment, $0.2 \mathrm{~mm}$; number of layers, 20).
$1273 \mathrm{~K}$ for different durations. It could be clearly seen that the intensity of $\alpha_{2}$ peaks $\left\{(200) \alpha_{2}\right.$ and (201) $\left.\alpha_{2}\right\}$ were considerably reduced after annealing for $3 \mathrm{~h}$. The peak heights did not change substantially even after annealing for $90 \mathrm{~h}$.

The DLF samples annealed in the $\alpha$ phase region at $1653 \mathrm{~K}$ for $0.5 \mathrm{~h}$ and subsequently air cooled exhibited coarse and lamellar microstructure as shown in optical and BSE micrographs in figures $16 \mathrm{~A}$ and $16 \mathrm{C}$, respectively. The lamellae of $\alpha_{2}$ and $\gamma$ phases were found to be nucleated at the grain boundary of the prior $\gamma$ grains. However, in between these packets of lamellae small regions of supersaturated single $\gamma$ phase were seen. This suggested that transformation of $\alpha$ phase to $\left(\alpha_{2}+\gamma\right)$ phase was not complete (figures $16 \mathrm{~A}$ and $\mathrm{C}$ ). When these air cooled samples were subsequently annealed at $1073 \mathrm{~K}$ for $3 \mathrm{~h}$ then complete transformation of $\alpha$ to $\left(\alpha_{2}+\gamma\right)$ phase could be observed (figures $16 \mathrm{~B}$ and $\mathrm{D}$ ).

\section{Discussion}

In the preliminary study of the DLF process of TiAl alloy component the observation of increase in the oxygen content will not affect the data but it will influence the detail of the microstructure to some extent. In the present study the accurate measurement of the thermal history such as temperature and temperature gradient during the sample build up for a range of condition has not been carried out. Therefore, precise interpretation of the complex microstructure of DLF sample would be impossible. For that reason the discussion in this paper on the development of microstructure is qualitative in nature.

The DLF process employs a high power density laser beam with energy inputs ranging from $10^{-2}$ to $1 \mathrm{~J} \mathrm{~mm}^{-2}$, which results in rapid melting of the feed powder and base metal. This also produces sharp temperature gradients $\left(\approx 10^{4}\right.$ to $10^{5} \mathrm{~K} / \mathrm{cm}$ ) between the solid and the liquid because almost negligible amount of thermal energy is conducted into the base metal. Since the solid/liquid contact is quite intimate, the melt rapidly solidifies with cooling rates of $10^{4}$ to $10^{8} \mathrm{KS}^{-1}$ depending upon the melt layer thickness (Basu and Date 1992; Hoadley and Rapaz 1992; Breinan and Kear 1998). Thus the high cooling rate associated with the laser melting process is the reason for the observation of fine microstructure in the DLF samples (Gilgren and Kurz 1996; Mohanty and Mazumdar 1998). The variation of the microstructure with laser power and other processing parameters essentially depends upon the time of interaction between powder of the solid sample and the laser beam (Gilgren and Kurz 1996; Breinan and Kear 1998; Mohanty and Mazumdar 1998). A particular combination of power density and interaction time defines a specific operational regime of the DLF process and results in a unique temperature gradient $(G)$, solidification rate $(R)$ and cooling rate $(T=G R)$. By 
changing the thermal condition e.g. increase in the ratio of $G / R$, results in the progressive change in the solidification characteristics from dendritic to cellular dendritic to planar front growth. Higher cooling rate $(G R)$ reduces the diffusion paths and results in finer microstructure. Thus, the ratio of $G / R$ controls the character of the microstructure, whereas, the product $(G R)$ determines the scale of the microstructure.

A longer interaction time or a higher heat input due to slow laser scanning speed and higher laser power density result in the superheated molten pool and high surface temperature. The liquid thus takes a longer time for solidification to start and the temperature of the base material becomes higher which results in lower temperature gradient of the interface and lower cooling rate. Thus, a coarse dendritic microstructure is observed, as would be expected (Gilgren and Kurz 1996). On the other hand, for the shorter interaction time or lower heat input because of low laser power or faster laser scanning speed, superheating is not as large and the average temperature gradient at the interface is high leading to faster cooling rate of a finer structure (figure 3C). The geometry of the clad bead in the DLF process is also a function of the processing parameters (Srivastava et al 2000). A lower laser power or higher powder flow rate will not heat the melt pool sufficiently. This will lead to the higher surface tensions
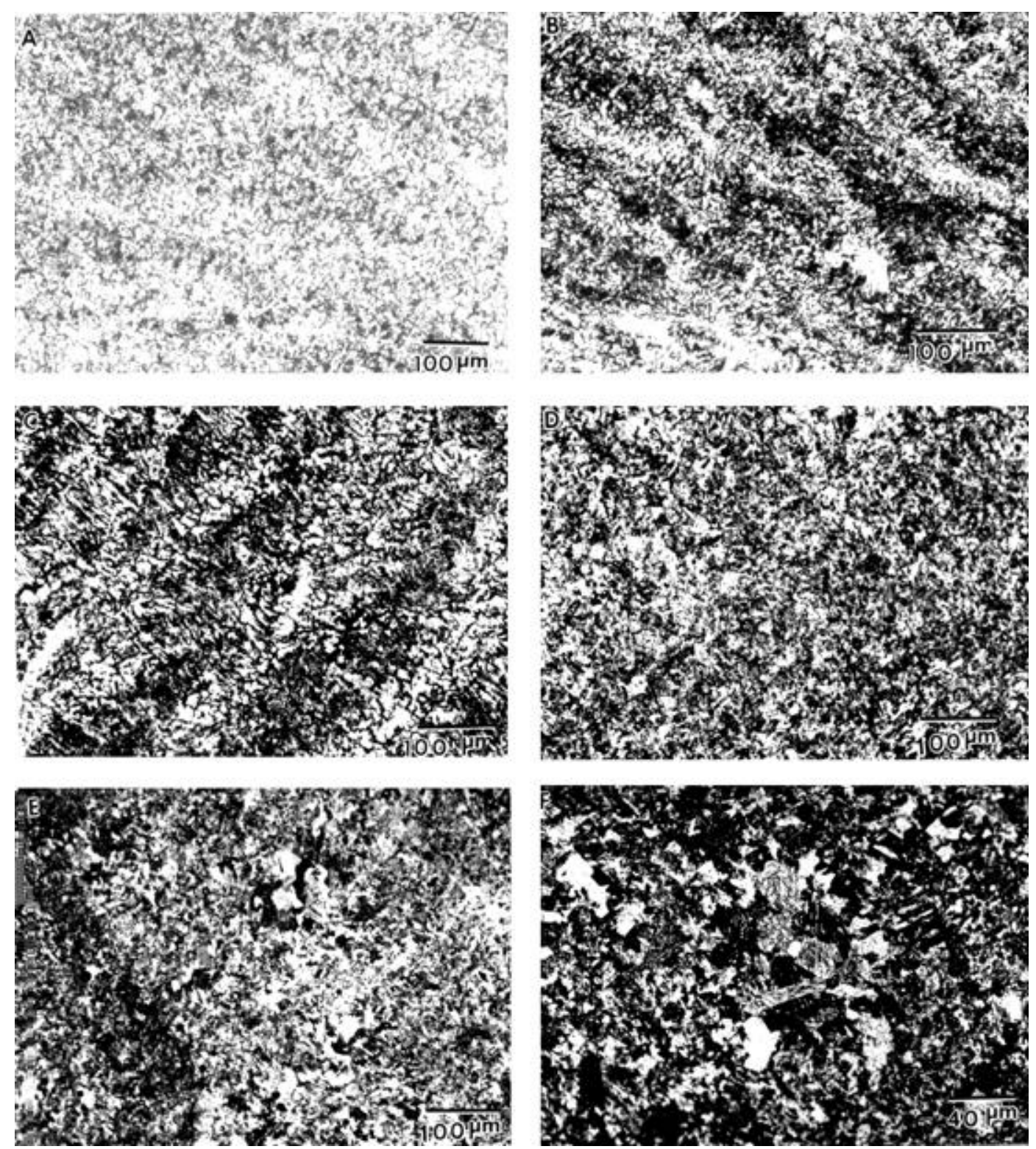

Figure 12. Optical micrographs of heat treated DLF samples of $\mathrm{Tl}_{48} \mathrm{Al}_{2} \mathrm{Mn}_{2} \mathrm{Nb}$ alloy: $\mathbf{A}$. as fabricated DLF sample, B. 973 K/300 h, C. 1073 K/24 h, D. 1073 K/200 h, E. 1273 K/24 h, and F. 1273 K/100 h (laser power, $400 \mathrm{~W}$; laser scanning speed, $8 \mathrm{~mm} / \mathrm{s}$; powder feed rate, $3 \mathrm{~g} / \mathrm{min}$; $z$-increment, $0 \cdot 2 \mathrm{~mm}$; number of layers, 20). 

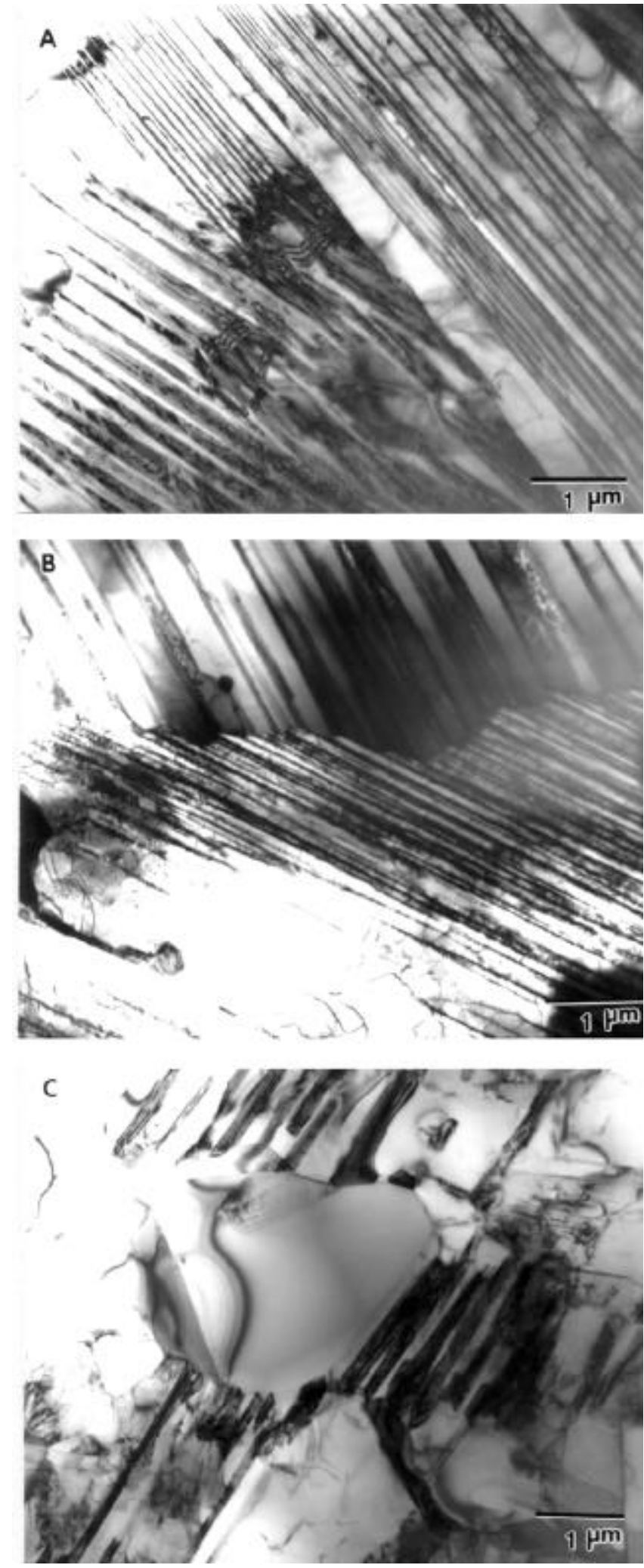

Figure 13. Many beam TEM micrographs of DLF samples of $\mathrm{Tl}_{48} \mathrm{Al}_{2} \mathrm{Mn}_{2} \mathrm{Nb}$ alloy heat-treated at different temperatures for different duration: A. $973 \mathrm{~K} / 100 \mathrm{~h}$; B. $1073 \mathrm{~K} / 24 \mathrm{~h}$ and C. $1073 \mathrm{~K} / 200 \mathrm{~h}$ (laser power, $400 \mathrm{~W}$; laser scanning speed, $8 \mathrm{~mm} / \mathrm{s}$; powder feed rate, $3 \mathrm{~g} / \mathrm{min}$; $z$-increment, $0.2 \mathrm{~mm}$; number of layers, 20).
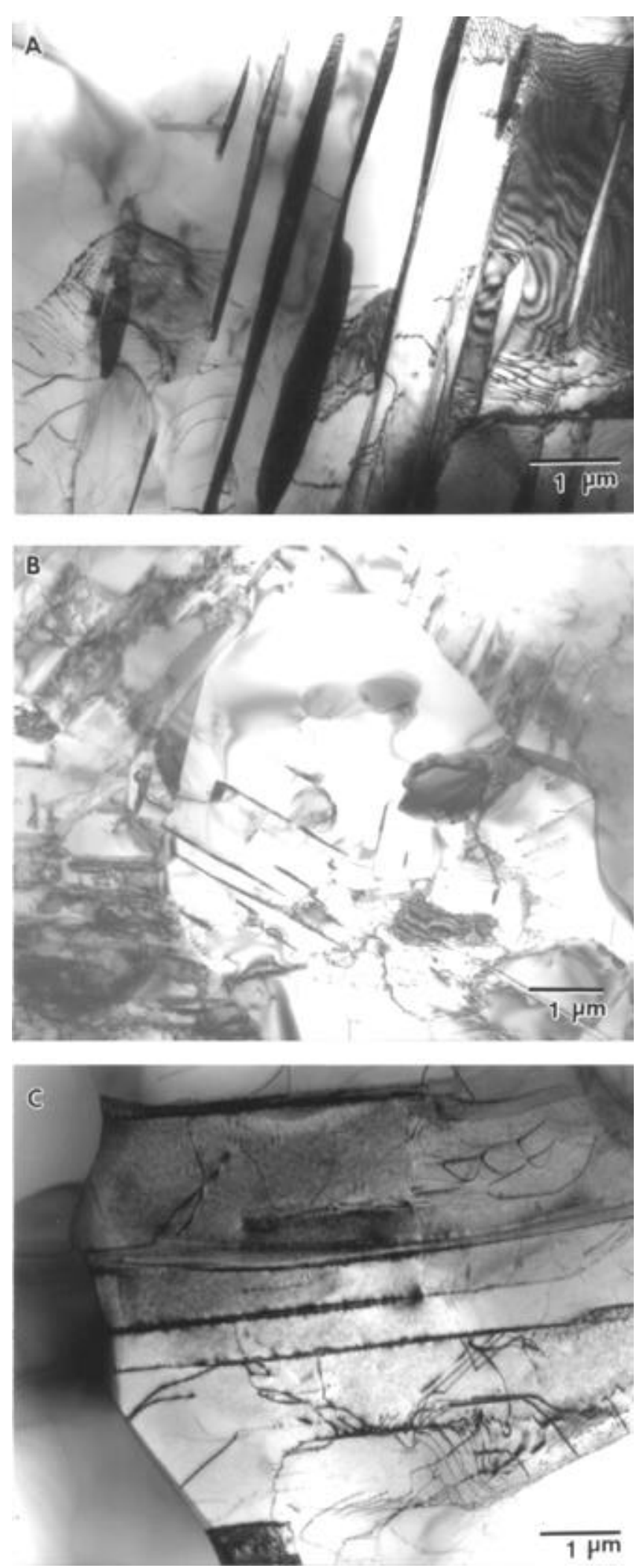

Figure 14. Many beam TEM micrographs of heat-treated DLF samples of $\mathrm{Tl}_{48} \mathrm{Al}_{2} \mathrm{Mn}_{2} \mathrm{Nb}$ alloy at $1273 \mathrm{~K}$ for duration $\mathbf{A}$. $3 \mathrm{~h}$, B. $24 \mathrm{~h}$ and C. $100 \mathrm{~h}$ (laser power, $400 \mathrm{~W}$; laser scanning speed, $8 \mathrm{~mm} / \mathrm{s}$; powder feed rate, $3 \mathrm{~g} / \mathrm{min}$; $z$-increment, $0 \cdot 2 \mathrm{~mm}$; number of layers, 20). 


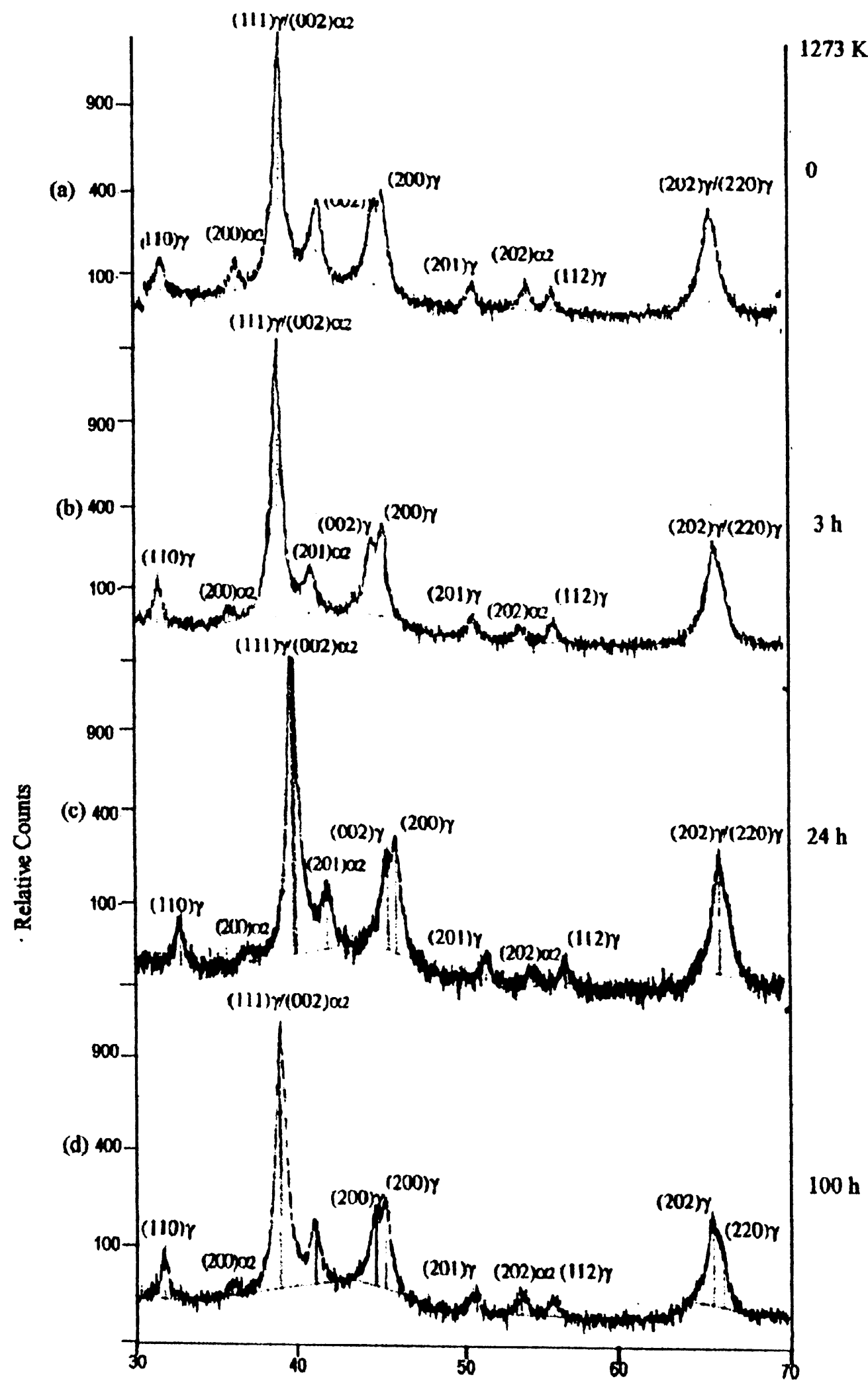

20

Figure 15. XRD of DLF samples of $\mathrm{Tl}_{48} \mathrm{Al}_{2} \mathrm{Mn}_{2} \mathrm{Nb}$ alloy heat treated at $1273 \mathrm{~K}$ for different durations: (a) conventionally fabricated, (b) $3 \mathrm{~h}$, (c) $24 \mathrm{~h}$ and (d) $100 \mathrm{~h}$ (laser power, $400 \mathrm{~W}$; laser scanning speed, $8 \mathrm{~mm} / \mathrm{s}$; powder feed rate, $3 \mathrm{~g} / \mathrm{min}$; $z$-increment, $0.2 \mathrm{~mm}$; number of layers, 20 ). 
of the melt pool and will result in cylindrical geometry. For such conditions heat dissipation will be poor resulting in low cooling rate and dendritic microstructure (figure 7A).

The DLF process is multi-layer deposition process, where the preceding layers become preheated or partially melted in the subsequent deposition, thus, cooling rate and hence the microstructure evolution are generally affected. The extent of heat affected zone (HAZ) in every subsequent deposition will be determined by the power density and the interaction time, i.e. the choice of processing parameters. This could be the reason for the observation of the imperfect lamellae and the variation in the morphology and microstructure of each individual laser deposited layer. In the case of higher scanning speed in comparison to the lower scanning speed this effect is more prominent. This is due to the fact that when the laser scanning speed is slower, the interaction time is larger resulting in lower temperature gradient and larger melt depth, a coarser microstructure between two layers (Srivastava et al 2000).

The explanation for the observation of the heterogeneous microstructure in the laser-fabricated sample is that this alloy solidifies as $\gamma$ phase and the remaining Al-rich liquid solidifies as $\gamma$ phase. The $\gamma$ phase on further cool- ing transforms to the $\left(\alpha_{2}+\gamma\right)$ phase. The lamellae spacing and width depends upon the number of potential defect sites present on the grain boundary, which will be large in rapidly cooled samples. This accounts for the fine lamellae in the microstructure of the DLF sample (Gilgren and Kurz 1996; Mohanty and Mazumdar 1998). The variation in the spacing of the lamellae in the microstructure laser fabricated samples can be attributed to the different cooling rate experienced with different laser power level (figure 9). The volume fraction of the $\alpha_{2}$ phase in $\gamma$-TiAl alloy is known to increase with increase in the cooling rate and increase in the oxygen content. Higher cooling rate in the laser fabrication process is responsible for showing stronger X-ray peaks of the $\alpha_{2}$ phase in the DLF samples. Higher cooling rate in the DLF process also results in the finer grain size which may be responsible for showing a wider single peak for $(002)_{\gamma}$ and $(200)_{\gamma}$ peaks and $(202)_{\gamma}$ and $(220)_{\gamma}$ peaks in the laser fabricated samples (figure 10).

The heat treatment studies indicate that the microstructure of DLF sample remains stable up to $973 \mathrm{~K}$ even after annealing for very long times. However, the microstructure was unstable when DLF samples were heat treated at $1073 \mathrm{~K}$ for slightly longer duration. In this case, the microstructure was fully recrystallized with negli-
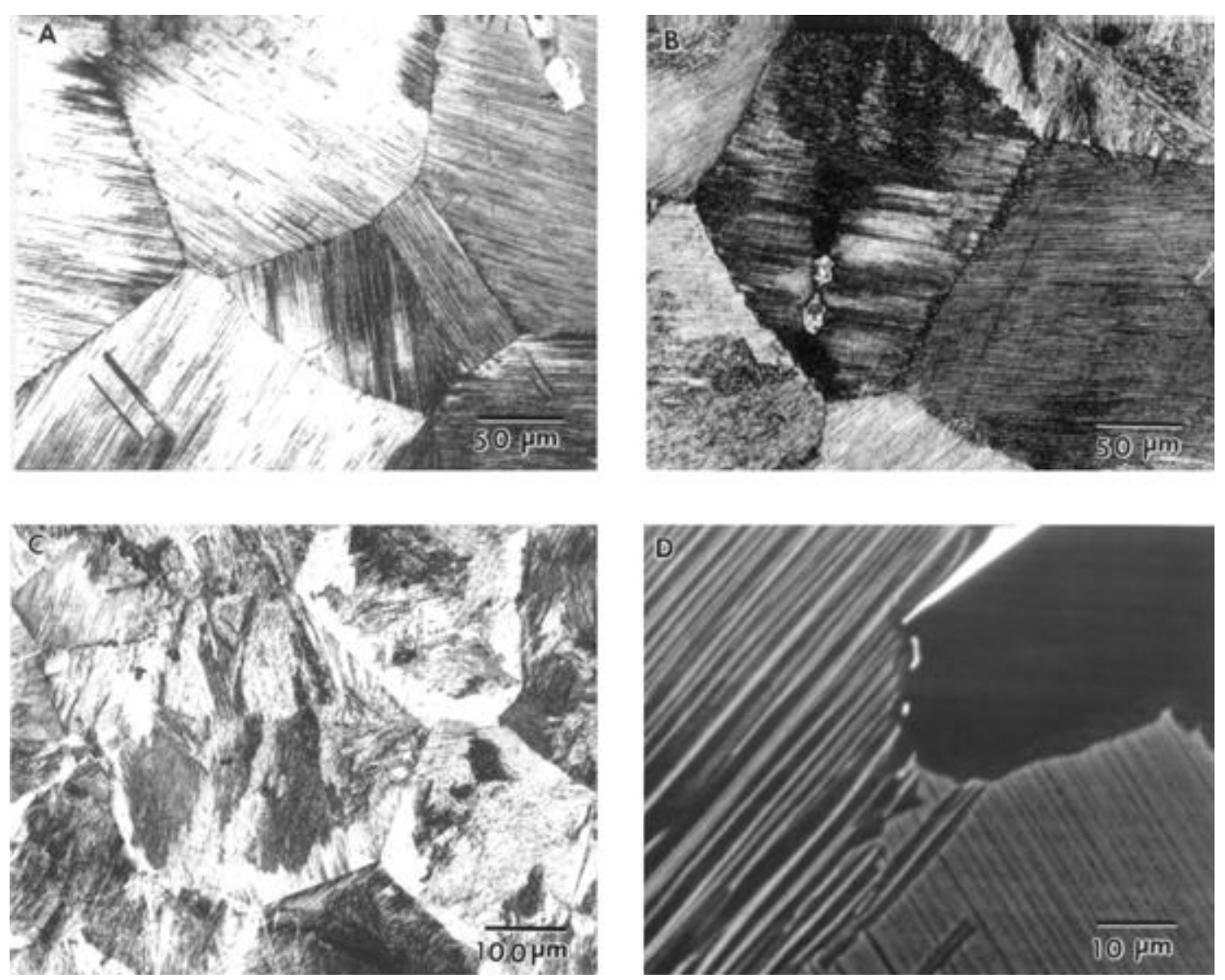

Figure 16. Micrographs of DLF samples of $\mathrm{Tl}_{48} \mathrm{Al}_{2} \mathrm{Mn}_{2} \mathrm{Nb}$ alloy heat treated at $1653 / 0 \cdot 5 \mathrm{~h}$ and subsequently air cooled at A. optical, C. BSE and heat treated at $1653 / 0.5 \mathrm{~h}$ followed by air cooling and annealing at $1073 \mathrm{~K}$ for $3 \mathrm{~h}$, B. optical and D. BSE (laser power, $400 \mathrm{~W}$; laser scanning speed, $8 \mathrm{~mm} / \mathrm{s}$; powder feed rate, $3 \mathrm{~g} / \mathrm{min}$; $z$-increment, $0 \cdot 2 \mathrm{~mm}$; number of layers, 20 ). 
gible grain growth, which resulted in more homogeneous microstructure. Thus, annealing at $1073 \mathrm{~K}$ for $24 \mathrm{~h}$ may be ideal for obtaining a uniform microstructure in the DLF samples. Grain coarsening occurred through secondary recrystallization and grain growth when the samples were annealed at $1273 \mathrm{~K}$ resulting in complete elimination of the lamellar structure. Annealing in the $\alpha$ phase region followed by air cooling resulted in a coarser lamellar structure because of the higher transformation temperature. Insufficient time was responsible for the partial transformation of $\alpha$ to $\alpha_{2}+\gamma$. Further, annealing in $\left(\alpha_{2}+\gamma\right)$ region for short times could yield a fully lamellar microstructure. Thus, a uniform and homogeneous microstructure in the DLF samples could be obtained by this treatment although the microstructure was much coarser than that in the DLF sample.

\section{Conclusions}

The microstructure in the DLF samples depends strongly on the processing parameters. A variety of microstructure could be obtained by varying the laser power and scanning speed. The microstructural studies have shown that the microstructure of the DLF samples is heterogeneous in nature and extremely fine in comparison to the conventionally processed material. The fine microstructure is expected to improve the properties. A post heat treatment is required to obtain a uniform and homogeneous microstructure. The microstructure remains stable up to $973 \mathrm{~K}$ and rapid grain coarsening occurs at $1273 \mathrm{~K}$. Annealing of DLF samples at $1073 \mathrm{~K}$ for $24 \mathrm{~h}$ results in fully recrystallized uniform and fine microstructure. The compositional heterogeneity present in the laser-fabricated samples could be eliminated by this heat treatment. Annealing in the $\alpha$ phase field and subsequently air cooling it and annealing in $\alpha_{2}+\gamma$ phase region also gives rise to homogeneous and uniform microstructure. However, the microstructure was much coarser than that of the DLF sample.

\section{Acknowledgements}

The author wishes to thank Prof. M H Loretto for introducing to rapid prototyping technique and for valuable discussions. The encouragement and support of $\mathrm{Dr} S$ Banerjee and Dr G K Dey are gratefully acknowledged. The author would like to thank EPSRC for financial sup- port through a ROPA research award and through the main IRC grant.

\section{References}

Basu B and Date A W 1992 J. Heat \& Mass Trans. 351049

Breinan E M and Kear B H 1998 Laser materials processing (Amsterdam: North-Holland Publishing Company) p. 295

Deckard C R and Beaman J J 1987 14th Conf. on production research and technology, Michigan (New York: ASME) p. 447

Dimiduk D M, Hazzledine P M, Parthasarathy T A and Seshagiri S 1998 Metall. Mater. Trans. A29 37

Gilgren P and Kurz W 1996 Surface treatment and film deposition (Netherlands: Kluwer Academic Publishers) p. 77

Hoadley A F A and Rapaz M 1992 Metall. Trans. B23 631

Hu D, Godfrey A B, Blenkinsop P A and Loretto M H 1998a Metall. \& Mater. Trans. A29 918

$\mathrm{Hu}$ D, Godfrey A B and Loretto M H 1998b Intermetallics 6 413

Kim Y-W 1994 JOM 4630

Kim Y-W 1998 Intermetallics 6623

Kim Y-W and Dimiduk D M 1991 JOM 4340

Kruth J -P, Bonse J, Meyvaert I and Morren B 1997 Proceedings of the laser assisted net shape engineering (LANE97), (eds) M Geiger and F Vollertsen (Bamberg, Meisenbach: Institution of Manufacturing Technology) p. 93

Liu C T and Maziasz P Z 1998 Intermetallics 6653

Loretto M H, Godfrey A B, Hu D, Blenkinsop P A, Jones I P and Cheng T T 1998 Intermetallics 6663

Majumdar J, Choi J, Nagarathnam K, Koch J and Hetzner D 1997 JOM 4955

Maruyama K, Yamamoto R, Nakakuki H and Fujitsuna F 1997 Mater. Sci. Engg. A239-240 419

Matsuo T, Nozaki T, Asai T, Chang S Y and Takeyama M 1998 Intermetallics 6695

Mertz R, Prinz F B, Ramaswami K, Terk M and Weiss L E 1994 Solid free form fabrication (Austin, Texas: The University of Texas at Austin) p. 1

Mohanty P S and Mazumder J 1998 Metall. \& Mater. Trans. B29 1269

Morris M A and Leboeuf M 1997 Mater. Sci.Engg. A224 1

Ramanujan R V, Maziasz P J and Liu C T 1996 Acta Mater. 44 2611

Srivastava D, Chang I T H and Loretto M H 1999 Intermetallics 7 1107

Srivastava D, Chang I T H and Loretto M H 2000 Mater. \& Des. 21425

Steen W M, McLean M A and Shannon G J 1997 Proceedings of the laser assisted net shape engineering (LANE97), (eds) M Geiger and F Vollertsen (Bamberg, Meisenbach: Institution of Manufacturing Technology) p. 115 